\title{
Study of the obstetric outcome of breech presentation in pregnancy in a tertiary hospital in a rural area in Telangana, India
}

\section{Kavitha Kothapally*, Archana Uppu, Vijayalakshmi Gillella}

Department of Obstetrics and Gynecology, Bhaskar Medical College and Bhaskar General Hospital, Yenkepally, Moinabad, Telangana, India

Received: 14 March 2017

Accepted: 07 April 2017

*Correspondence:

Dr. Kavitha Kothapally,

E-mail: kavitha.nkothapally@gmail.com

Copyright: (C) the author(s), publisher and licensee Medip Academy. This is an open-access article distributed under the terms of the Creative Commons Attribution Non-Commercial License, which permits unrestricted non-commercial use, distribution, and reproduction in any medium, provided the original work is properly cited.

\section{ABSTRACT}

Background: The present study was undertaken to study the incidence, aetiology and obstetric outcome of breech presentation in pregnancy in a teaching hospital in a rural area.

Methods: The present retrospective observational study was conducted in the department of obstetrics and gynaecology at Bhaskar Medical College and Bhaskar General Hospital, Yenkepally, Telangana from May 2014 to March 2017. 50 cases of breech presentation were included in the study. Demographic data like age, parity, gestational age of first detection of breech, aetiological factors of breech, mode of delivery, neonatal outcome were noted from case records.

Results: The incidence of breech was $1.4 \%$ in pregnancies attending Bhaskar general hospital. $74 \%$ were in the age group of 20-24yrs \& $20 \%$ were in the age group of $25-29 y$ yrs. Primis accounted for $62 \%$ of the study group. Common etiologies of breech presentation were oligohydramnios $(28 \%)$ and uterine anomalies (28\%). No obvious fetal anomalies were noted. Majority $(96 \%)$ of cases were delivered by caesarean section for breech associated with oligohydramnios, gestational hypertension, intrauterine fetal growth restriction and preterm. Neonatal outcome was good in breech delivered by caesarean section.

Conclusions: Breech delivery is a high risk pregnancy with adverse fetal outcomes during pregnancy and labour. Though caesarean section for breech presentation is not universally recommended, caesarean section can reduce the perinatal mortality and morbidity compared to vaginal birth for term breech pregnancy. Mode of delivery should be decided based on the case and obstetrician's skill.

Keywords: Breech presentation, Maternal and fetal outcome, Mode of delivery

\section{INTRODUCTION}

Breech is the common nonvertex presentation in 3-4\% of pregnancies all over the world. ${ }^{1}$ Percentage of breech presentation and deliveries decreases with advancing gestational age, from $22 \%$ of births prior to 28 weeks to $7 \%$ of births at 32 weeks to $1-3 \%$ of births at term. ${ }^{1}$ Incidence decreases towards term due to spontaneous version. So, an active process is involved in limiting this spontaneous version and it results in breech presentation. ${ }^{2}$

Breech presentation results from uterine anomalies, cornuofundal insertion of placenta, placenta previa, oligohydramnios, fetal getal growth restriction, prematurity, short umbilical cord, fetal anomalies like hydrocephalus, swellings in front of the neck. ${ }^{1}$ Hence, we should look for the presence of uterine anomalies, site of placenta and fetal anomalies in all cases of breech presentation. Perinatal mortality is increased 3-4fold with breech presentation irrespective of the mode of delivery. ${ }^{1}$

Prematurity, cord prolapse and difficulties during vaginal breech delivery especially of the aftercoming head add to the increased perinatal mortality and morbidity following vaginal breech delivery. ${ }^{1}$ On the otherhand, through planned caesarean delivery, atleast at term, reduces the 
risk of increased perinatal mortality and morbidity compared to vaginal birth. ${ }^{1}$ But maternal morbidity is high in caesarean section. ${ }^{1}$ Hence, judicious decision regarding mode of delivery is vital.

\section{METHODS}

The present retrospective observational study was conducted at Bhaskar medical college and Bhaskar general hospital, Yenkepally from May 2015 to March 2017. 50 pregnancies with breech presentation after 34 weeks were included in the study. Since it was a retrospective study, consent could not be taken.

The case records of study group were reviewed for demographic data like age, parity, gestational age of breech diagnosis by ultrasound and the presence of aetiological factors. Gestational age of delivery and mode of delivery were noted. Indications for caesarean section, maternal complications and perinatal outcome were noted.

\section{RESULTS}

In present study, the incidence of breech was $1.4 \%$ compared to $3 \%$ in a study by Saira Das et al, $2.1 \%$ in a study by Abha Singh et al and $4.2 \%$ in the Cameroonian nullipara. ${ }^{1,3,4}$

Table 1: Demographic data(n=50).

\begin{tabular}{|lll|}
\hline Age in years & No. of cases & $\%$ \\
\hline$<19$ & 0 & 0 \\
\hline $20-24$ & 37 & 74 \\
\hline $25-29$ & 10 & 20 \\
\hline $30-34$ & 3 & 06 \\
\hline Parity & & \\
\hline Primi & 31 & 62 \\
\hline Gravida 2 & 12 & 24 \\
\hline Gravida 3 and above & 07 & 14 \\
\hline
\end{tabular}

From Table 1, we see that $74 \%$ were in the age group of $20-24 y$ rs and $20 \%$ were in the age group of $25-29 y r s$ against $48.5 \%$ in $21-25 y r s$ and $24.5 \%$ in $26-30 y r s$ in a study by Sonali et al. ${ }^{2}$

Table 2: gestational age at which breech was diagnosed by ultrasound $(n=50)$.

\begin{tabular}{|lcc|}
\hline Gestational age & No. of cases & $\%$ \\
\hline <33wks & 20 & 40 \\
\hline 37-36wks & 10 & 20 \\
\hline In labour & 10 & 20 \\
\hline
\end{tabular}

Primis constituted $62 \%$ and multis formed $38 \%$ against $53 \%$ of primis in the study by Sonali et al and $40.4 \%$ in the study by Abha Singh etal. ${ }^{2,3}$

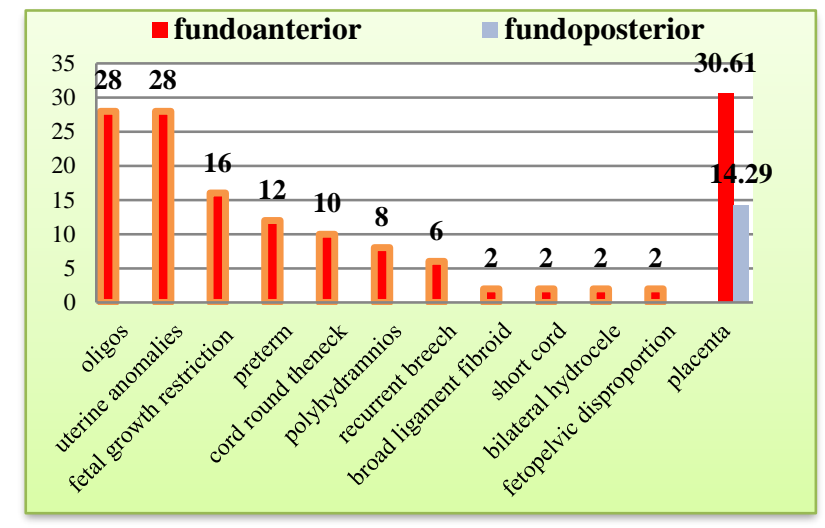

Figure 1: Aetiology of breech presentation in percentage $(n=50)$.

From Figure 1, we see that the commonest etiology was oligohydramnios (28\%) against 3\% in the study by Sonali et al. $^{2}$ Uterine anomalies were seen in $28 \%$. Cord round the neck was seen in $10 \%$. Though no case had placenta previa, fundoanterior placenta was seen in $30.61 \%$ and fundoposterior placenta in $14.29 \%$. Short cord, seen in $2 \%$ of cases, is also a cause for breech presentation as shown by Adinma's study in which 1000 cases were observed to have short cord. ${ }^{5}$

Recurrent breech was observed in $6 \%$. No obvious fetal anomalies were detected in the breech cases similar to the Cameroonian study. ${ }^{4}$

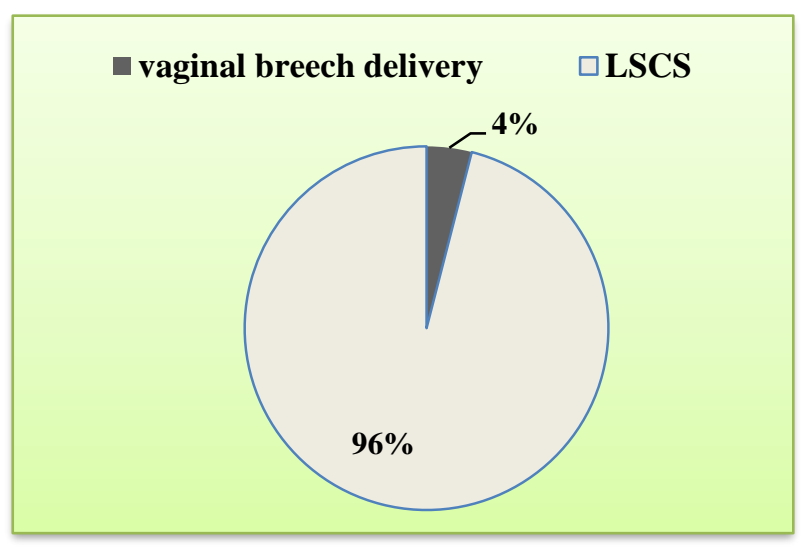

Figure 2: Mode of delivery $(n=50)$.

$96 \%$ of the cases underwent caesarean section as shown in the Figure 2 against $74 \%$ in study by Sanjivni et al and $33.3 \%$ in Cameroonian study on breech. ${ }^{6,4}$ In our study, only $4 \%$ had vaginal breech delivery as they were multi gravidae who presented in active labour and were preterm pregnancies. From Figure 3, we see that majority of the breech presentations delivered by caesarean section were primigravidae (58\%) similar to the study by Sanjivani et al. ${ }^{6}$ But in other studies caesarean incidence was $20.5 \%$ in primis by sonali et al and $11 \%$ primis in a study by Noraihan. ${ }^{2,7}$ 


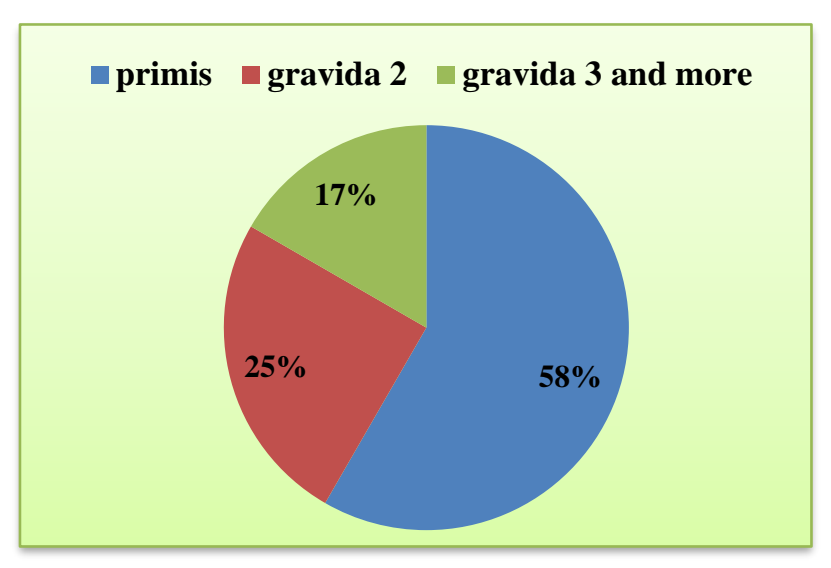

Figure 3: Incidence of LSCS in different parities $(n=48)$.

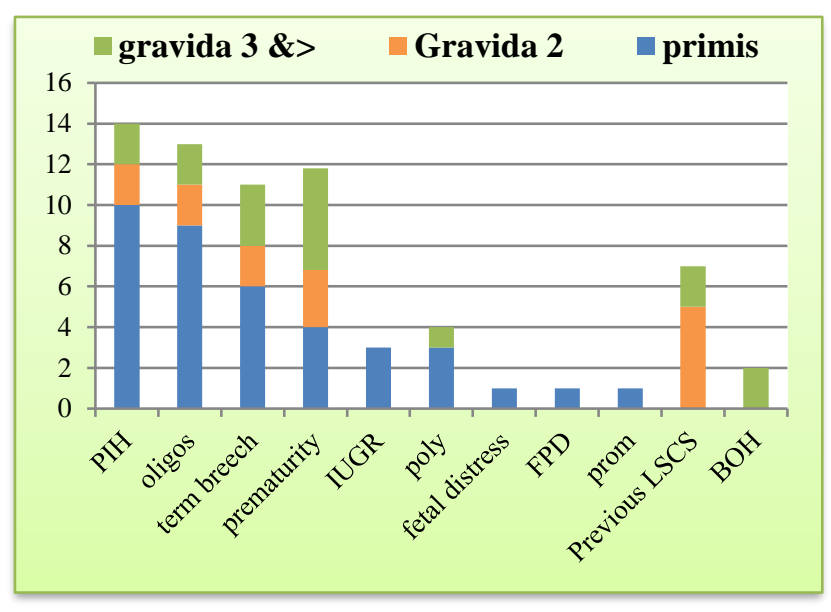

Figure 4: Indications of LSCS in breech in different parities $(n=48)$.

As shown in Figure 4, oligohydramnios and gestational hypertension were associated with breech in majority of cases undergoing caesarean section against study of Sonali et al, where post LSCS, bad obstetric history, gestational hypertension, oligos and fetal growth restriction were the indications for caesarean section. ${ }^{2}$

Table 3: Maternal complications $(n=50)$.

\begin{tabular}{lll}
\hline Complication & No. of cases & $\%$ \\
No complication & 45 & 90 \\
\hline Postpartum hemorrhage & 04 & 08 \\
\hline PROM & 01 & 02 \\
\hline
\end{tabular}

Table 3 shows that maternal morbidity was $10 \%$ in caesarean section against $3.4 \%$ in caesarean section and $4.2 \%$ in vaginal delivery in a study by Abha et al. ${ }^{3}$

From Table 4 , term breech was seen in $88 \%$ of cases against $77.3 \%$ in the study by Abha Singh et al. ${ }^{3} 56 \%$ had birth weight of $2.6-3 \mathrm{~kg}$ and $14 \%$ had $3.1-3.5 \mathrm{~kg}$ birth weight
Table 4: Neonatal outcome $(n=50)$.

\begin{tabular}{|lll|}
\hline Fetal maturity & No. of cases & $\%$ \\
\hline Preterm (34-36 weeks) & 6 & 12 \\
\hline Term & 44 & 88 \\
\hline Birth weights & & \\
\hline$\leq 2.5 \mathrm{~kg}$ & 15 & 30 \\
\hline $2.6-3 \mathrm{~kg}$ & 28 & 56 \\
\hline $3-3.5 \mathrm{~kg}$ & 7 & 14 \\
\hline
\end{tabular}

Table 5 shows that the neonatal morbidity in the form of respiratory distress and prematurity was $50 \%$ in vaginal breech delivery. $72 \%$ of the breech presentations delivered by caesarean did not have any neonatal problems. Similar satisfactory perinatal outcome was seen in $95 \%$ neonates delivered by caesarean section in a study. ${ }^{6,8}$

Table 5: Neonatal morbidity $(n=50)$.

\begin{tabular}{|lll|}
\hline Complications & No. of cases & $\%$ \\
\hline No complications & 36 & 72 \\
\hline Sublaxation of hips & 1 & 02 \\
\hline NICU admissions & 6 & 12 \\
\hline Preterm & 2 & 33.33 \\
\hline IUGR & 2 & 33.33 \\
\hline Moderate RDS & 2 & 33.33 \\
\hline Respiratory distress syndrome & 8 & 16 \\
\hline
\end{tabular}

\section{DISCUSSION}

The incidence of breech presentation was more in primigravidae in our study unlike studies by Sonali et al and Abha et al where multis dominated. In more than $50 \%$ of cases breech persisted from 33 weeks of gestation. ${ }^{2,5}$ Most of the breech presentations had an aetiological factor like oligohydramnios, uterine anomalies, short cord, fetal growth restriction, prematurity unlike other studies which showed etiology in only $7-15 \%$ of breech presentation. ${ }^{9}$ Fundoanterior and fundoposterior placental positions were associated with breech in ourstudy. Cornuofundal placenta was seen in $70 \%$ of the cases in a study by Pavol Zuber. ${ }^{5}$

Breech presentation may be a sign of fetal anomaly especially cardiovascular, central nervous system and musculoskeletal anomalies. ${ }^{10}$ Hence, it is necessary to look by ultrasound and during cesarean for the presence of fetal anomalies, uterine anomalies and placental site, especially if there is a recurrent breech presentation. From this study, we see that caesarean section is the preferred mode of delivery at our institute. Only multigravidae with preterm babies presenting in active labour could be allowed vaginal breech delivery. Most of the breech presentations were in primigravidae similar to another study by Sanjivani et al. ${ }^{6}$ They were associated with problems like oligohydramnios, gestational hypertension, fetal growth restriction, prematurity, polyhydramnios and fetopelvic disproportion due to big 
baby. Multis with breech were associated with previous caesarean section. Due to small family norms, lack of universal availability of skilled obstetrician for vaginal breech delivery and associated obstetric problems, the incidence of caesarean section was high in our study. Neonatal outcome was good and maternal morbidity was less similar to a study by sanjivni et al. ${ }^{6}$

Vaginal breech delivery was previously the method of delivery for breech till Hannah et al proposed that to reduce perinatal mortality and morbidity, all breech should be delivered abdominally. ${ }^{11}$ In term breech, there is no difference in maternal mortality and morbidity between the two methods of delivery. ${ }^{12}$ Randomised multicentric term breech trial by Hannah ME etal published in 2000 showed that a planned elective caesarean section reduces the risk of adverse perinatal outcomes compared to planned vaginal breech delivery. ${ }^{12}$ Consequently, in 2001, The ACOG recommended caesarean delivery for term singleton breech. ${ }^{7}$

Some clinicians have recommended a policy of caesarean section for breech at term based on anecdotal experiences and medicolegal concerns. ${ }^{12}$ Others who are experienced with vaginal breech delivery have continued to recommend planned vaginal birth for selected cases but under the guidance of a skilled obstetrician. ${ }^{12}$ Reduction in vaginal breech delivery may lead to less experienced obstetricians in situations where vaginal breech delivery is unavoidable like in undiagnosed breech in advanced labour or delivery of second twin. ${ }^{13}$ Hence in selected cases of breech presentation, vaginal breech delivery should be attempted with patient's consent, availability of a skilled obstetrician and in a double setup for emergency caesarean section. ${ }^{13,14}$ External cephalic version for breech presentation, attempted from 36 weeks, is an alternative to reduce the incidence of breech at term and the incidence of caesarean section. ${ }^{14-16}$

\section{CONCLUSION}

Though caesarean section yields better perinatal outcome, present obstetric recommendations are for vaginal breech delivery so that vaginal breech delivery does not become a dying art.

\section{Funding: No funding sources}

Conflict of interest: None declared

Ethical approval: The study was approved by the Institutional Ethics Committee

\section{REFERENCES}

1. Dars S, Malik S, Bhurgri A. Is breech still being delivered vaginally? A comparative study. Int J
Reprod Contracep Obstet Gynaecol. 2014;3(1):1448.

2. Gaikwad S, Rokade R. Study of maternal and perinatal outcome of breech in vaginal and operative delivery in a university hospital. Int Med $\mathrm{J}$. 2014;1(6):252-8.

3. Singh A, Mishra N, Dewangan R. Delivery in breech presentation: the decision making. J Obstet Gynaecol India. 2012;62(4):401-5.

4. Elie N, Nelson FJ, Luc K, Chanchu NP. Outcome of breech deliveries in Cameroonian nulliparous women. J Obstet Gynaecol India. 2012,62(5):531-5.

5. Zubor P. Repetitive breech presentation at term. Slovakia case report. 2013:628572.

6. Sanjivani, Wanjani A. Breech delivery a changing scenario. Int J Reprod Contracep Obstet Gynaecol. 2015;2:384-7.

7. Nordin MN. An audit of singleton breech deliveries in a hospital with a high rate of vaginal delivery. Malays J Med Sci. 2007;14(1):28-37.

8. Dongol A, Regmi S, Manandhar S, Kc S. Breech presentation among nullipara at term: an indication for caesarean section. Kathmandu Univ Med J. 2012;10(4):66-9.

9. Duke AO, Duke CO, Onyegbule OA, Amajuoyi CC, Madu PI, Enyinnaya EB. Outcome of single breech term deliveries at the Federal Medical Centre, Owerri, South Eastern Nigeria: a five year review. Int J Res Med Sci. 2014;2:527-31.

10. Mostello D, Chang JJ, Bai F, Wang J. Breech presentation at delivery, a marker for congenital anomaly. J Perinatol. 2014;34(11-15).

11. Abduljabbar HSO, Fetyani DM, Sait HK, Almagrabi FJ, Alsaggaf AE. Breech presentation: prevalence, outcome, review of 512 cases of breech. ARC J Gynaecol Obstet. 2016;1(2):2-6.

12. Hannah ME, Hannah WJ, Hewson SA, Hodnett ED, Saigal S, Willan AR. Planned caesarean section versus planned vaginal birth for breech presentation at term: a randomised multicentre trial. Lancet. 2000;356:1375-83.

13. Vistad I, Cvancarova M, Hustad BL, Henriksen T. Vaginal breech delivery: results of a prospective registration study. BMC Pregnancy and Childbirth. 2013;13:153.

14. RCOG. The management of breech presentation. guidelines No. 20b;2006. Available from: https://www.rcog.org.uk/globalassets/documents/gui delines/gtg-no-20b-breech-presentation.pdf

15. Nahid F. Outcome of singleton term breech cases in the pretext of mode of delivery. J Pak Med Assoc. 2000;50:81-5.

16. Ranzcog coll. Management of breech presentation at term. Obst 11: college statement. Ranzcog; 2013.

Cite this article as: Kothapally K, Uppu A, Gillella V. Study of the obstetric outcome of breech presentation in pregnancy in a tertiary hospital in a rural area in Telangana, India. Int $\mathbf{J}$ Reprod Contracept Obstet Gynecol 2017;6:2040-3. 